Egyptian harbour. In Greece, deep bays and long arms of the sea made excellent natural harbours; moreover, Greece was divided into many small States, each with its own port. Athens used first the broad open bay of Phalerum, where ships were beached in sight of the city. That arrangement, however, had several strategical and navigational disadvantages, and in 493 B.c. Themistocles persuaded the Athenians to develop the fine natural harbour of Piræus. At some places artificial harbours had to be constructed, of which that at Eleusis was typical.

The Romans had to face difficult technical problems when their growing commerce demanded effectual shelter. They introduced many new methods, the most outstanding of which were the use of the arch, the cofferdam, hydraulic cement (pozzuolana), and the driving of piles in deep water. The Roman ideal plan was an artificial harbour having the two incurving breakwaters of the Greeks, with the Roman addition of a short protecting mole or island breakwater in front of the entrance. The sand problem caused considerable trouble, and silting drove the Romans from Antium and the Tiber and caused the failure of the harbour of Ostia. Trajan accordingly took measures to provide a new harbour for Rome higher up the coast, which under its modern name of Civita Vecchia is now the principal port of Rome. The Roman Empire was followed by more than 1,000 years of acquiescence, or even retrograde action, in harbour engineering, and it was not until the engineering revival in about the middle of the eighteenth century that such ambitious schemes were again attempted.

\section{Electric Fan Ventilation}

THE necessity for air-raid precautions and for black-outs has introduced several problems besides that of lighting which have to be studied. In the Electrician of October 11 a discussion is given of some important considerations with respect to electric fan ventilation. One attendant result of most of the measures taken for black-out and sandbagging against the effect of bombing is the restriction of the natural air-flow and an increase in the heat dissipation due to augmented lighting. Since it is known that a relatively high proportion of carbon dioxide can be permitted without any ill-effects, in big ventilation systems a large percentage of the air is recirculated in order to conserve the heat. Hence where the volume of air relative to the number of persons concerned is large, an air disturber serves a useful purpose in both summer and winter. In smaller places the most usual method of ventilation under ordinary peace conditions is by exhaust, but it is now common to take into consideration the presence of gas from enemy action, and for such eventualities it is necessary to take in a supply of clean air by means of an intake placed so as to be above the level likely to be contaminated. Complete protection is afforded by first passing the air through a filter.

The number of air changes required in various public buildings is laid down by law, but for offices, shops, factories, etc., the figure depends on the work to be carried out and the types of processes involved. For the average type of office, two to three air changes an hour will be sufficient, for dining-rooms four to six, but for kitchens fifteen to twenty changes may be necessary. Where long runs of ducts are necessary for extracting from a number of rooms, the resistance of the air in the ducts may be more than a propeller fan can deal with, and a centrifugal fan should be used.

\section{Primitive Trepanning}

THE surgical operation of removing a circular piece of bone from the human skull of the living is one which it has long been known was practised by primitive man with, relatively speaking, some frequency. The practice had a wide distribution in both time and space, ranging chronologically from the early neolithic period to modern times and geographically from many parts of prehistoric Europe (and in historical times in Serbia) to the Pacific. Late prehistoric or early historic examples are known from the Caucasus, Palestine and Siberia, while the practice was frequent in pre-Inca and Inca Peru and Bolivia. In the last-named region, however, there is a possibility that there has sometimes been confusion with a syphilitic lesion. The frequency of a depressed fracture in a stone age culture using the stone axe as a favourite weapon must, obviously, he held responsible for the introduction of the operation; but there is evidence that it was also employed for the alleviation of any violent pain in the head. A variant practised for the relief of headache in New Guinea is drilling with a boco-drill and flint fleam. The appearance of amulets made of circular pieces of bone taken from a trepanned skull, which are among prehistoric finds, points to the infiltration of magical ideas-never long unobserved in primitive methods of healing-and affords an explanation in part for the performance of the operation at or after death.

The uniformity in the technique of the operation, the cutting of a circular groove with a stone implement, or rarely a series of drill holes, or grooved straight lines forming a rectangle-suggests the possibility of its distribution by cultural diffusion. Mr. Stuart Piggott, however, in a study of the practice in prehistoric Europe, to which reference is made on p. 621, holds the view that in its earliest appearances when it is a remedial measure for individual injury it is to be regarded as an independent invention, but that when it becomes a cult -a justifiable reference from the evidence-we are justified in looking for links between instances in which the rite was practised. Working from the early centre of greatest frequency in the Lozère valley of southern France and ingeniously associating the rite of trepanation with megalithic building and the cult of the megalithic goddess, he traces it to the mouth of the Garonne along the line of the Bronze Age trade route along the oolite and to the Paris basin, whence it spread with the SOM culture characteristic of that area in this period. 